\title{
PENGARUH KUALITAS PELATIHAN TERHADAP LOYALITAS PELANGGAN ORIFLAME DI LINGKUNGAN MAHASISWA ADMINISTRASI NIAGA POLITEKNIK NEGERI JAKARTA
}

\author{
Tiyu Ratri, Azwar dan Dra.Mawarta Onida
}

Mahasiswa Administrasi Bisnis Terapan Politeknik Negeri Jakarta

Email: tiyuratri92@gmail.com

\begin{abstract}
Abstrak
Penelitian ini membahas mengenai pengaruh kualitas pelayanan terhadap loyalitas pelanggan.Penelitian ini menggunakan analisis kuantitatif.Tujuan penelitian ini adalah mendeskripsikan analisis pengaruh variabel X (kualitas pelayanan) terhadap variabel Y (loyalitas pelanggan).Sampel yang digunakan dalam penelitian ini berjumlah 50 orang. Adapun metode pengambilan sampel dengan menggunakan sampling kuota,sampling purposive,dan non random sampling.Sebelum dilakukan penelitian,terlebih dahulu dilakukan uji validitas dan reliabilitas terhadap 50 sampel yang digunakan untuk penelitian.Selanjutnya dilakukan uji korelasi sederhana (Korelasi Produk Moment),dan Regresi Linier Sederhana,Uji Koefisien Determinasi,Uji Signifikansi t.Dari hasil analisi korelasi sederhana didapat nilai korelasi antara kualitas pelayanan $(\mathrm{X})$ dengan loyalitas pelanggan $(\mathrm{Y})$ sebesar $\mathrm{R}=0,660$, hal ini menunjukkan bahwa hubungan yang kuat.Uji Koefisien Determinasi nilai korelasi $\mathrm{R}^{2}$ sebesar 0,660 dan nilai $\mathrm{R}$ square sebesar 0,436 menunjukkan besarnya pengaruh variabel $\mathrm{X}$ (kualitas pelayanan) terhadap variabel Y (loyalitas pelanggan). Pada uji t diketahui hasil dengan nilai t hitung sebesar 5,418,dimana nilai tersebut lebih besar dari t tabel yang di tentukan sesuai dengan taraf tingkat kesalahan $5 \%$ sebesar 1,686.Selain itu hasil perhitungan pada tabel signifikan menunjukkan hasil sebesar 0,000 ,dimana nilai tersebut lebih dari probabilitas signifikan yaitu 0,05 . Artinya adalah menunjukkan hasil bahwa terdapat pengaruh yang signifikan antara kualitas pelayanan terhadap loyalitas pelanggan pada produk Oriflame.
\end{abstract}

Kata Kunci: Kualitas Pelayanan,Loyalitas Pelanggan.

\section{Abstract}

This study explains about the influence of service quality toward on customer loyalty of Oriflame product.This study uses quantitative analysis. The purpose of this study is to describe the analysis of the influence of variable $X$ (service quality) to variable $Y$ (customer loyalty). The sample used in this study is about 50 people.The sampling method used quota sampling,purposive sampling,and non-random sampling.Prior to this research,first tested the validity and reliability of the 50 samples were used for the study,then followed by test of the simple correlation test (Product Moment Correlation),Simple Linear Regression, Coefficient of Determination Test, Test Significance t.From the simple correlation analysis results obtained score of the correlation between the Quality of Service $(X)$ and Customer Loyalty $(Y)$ amounted to $R=0.660$. It shows that there is a strong relationship. Coefficient Determination Test correlation value $R^{2}$ of 0.660 and the value of $R$ square of 0.436 indicates the magnitude of the effect of variable $X$ (service quality) to variable $Y$ (customer loyalty). At $t$ test with a known outcome $t$ value of 5.418, where the value is greater than t table which is determined according to the level of $5 \%$ error rate of 1.686. In addition the calculation results in significant table 
shows the results of 0,000, which the score is greater than a significant probability of 0.05.It means that the results show there is a significant influence between the service quality on customer loyalty of Oriflame Product.

Keywords: Quality of Service, Customer Loyalty

\section{PENDAHULUAN}

Saat mengkonsumsi suatu produk, pelanggan mengharapkan adanya pengalaman yang memuaskan. Harapan ini identik baik pada barang maupun jasa (Zeithaml, 1981). Pada pembelian produk berupa barang, misalnya kosmetika, beberapa pertimbangan akan masuk dalam kepuasan pelanggan. Hal tersebut bisa meliputi kesesuaian ukuran,harga, kualitas barang bahkan adanya perhatian yang bisa dimunculkan oleh kosmetika tersebut. Hal yang serupa terjadi pada penyajian layanan jasa, baik jasa pendidikan, hiburan, keuangan, hukum, medis maupun pernikahan. Masing-masing jasa membawa serangkaian atribut yang bisa atau tidak bisa menjadi sumber kepuasan bagi pemakai perorangan, dimana sumber-sumber kepuasan bagi satu orang bisa saja bukan sumber kepuasan bagi orang yang lain.

$$
\text { Pada umumnya, perusahaan }
$$

memproduksi beraneka ragam produk. Dengan keberanekaragaman produk tersebut menimbulkan persaingan pasar khususnya pada industri kosmetika kecantikan. Sehingga banyak hal yang perlu peningkatan kualitas produk mereka. Pada umumnya perusahaan memiliki strategi khusus dalam meningkatkan kualitas produknya. Perusahaan banyak melakukan hal dalam meningkatkan penjualan. Selain itu, ada pula perusahaan yang lebih fokus pada kualitas produk (brand) mereka.Persaingan antar pasar industri perawatan pribadi dan kosmetik semakin kompetitif. Hal ini terbukti dengan banyaknya jenis kosmetika di pasaran yang mempengaruhi sikap seseorang terhadap pembelian dan pemakaian barang. Oriflame merupakan salah satu perusahaan kosmetika yang bergerak dibidang Multi Level Marketing yang bermula di Stockholm,Sweden, tahun 1967 oleh dua orang bersaudara Jonas dan Robert af Jochnick.

Oriflame menyediakan semua alat penunjang tata rias baik lipgloss, lipstick, bedak, mascara, dan lain-lain yang dibutuhkan demi menunjang penampilan dikehidupan sosial. Selain itu juga ada krim perawatan wajah,tangan, kaki, daerah kewanitaan, dan bahkan kuku sebagai extra treatment bagi yang ingin berpenampilan lebih cantik dan mempesona.

Saat ini, konsep kualitas layanan telah menjadi faktor yang dominan terhadap keberhasilan suatu organisasi. Kualitas pelayanan tidak hanya di adopsi oleh lembaga-lembaga penyelenggara jasa-jasa komersial, tetapi $\mathrm{n}$ terhadap telah memasuki lembaga-lembaga pemerintah, yang selama ini resisten terhadap tuntutan kualitas pelayanan publik yang baik. Pelayanan prima sangat dibutuhkan terutama di industri jasa mengingat konsumennya mempunyai keinginan yang berbeda-beda dan yang selalu ingin dipenuhi dan dipuaskan.

\section{Identifikasi Masalah}

Berdasarkan uraian di atas penulis mengidentifikasi masalah sebagai berikut :

a. Seberapa besar pengaruh kualitas pelayanan terhadap konsumen di lingkungan mahasiswa Administrasi Niaga Politeknik Negeri Jakarta?

b. Seberapa besar pengaruh loyalitas konsumen di lingkungan mahasiswa Administrasi Niaga Politeknik Negeri Jakarta? 


\section{Perumusan Masalah}

Dari latar belakang masalah, identifikasi masalah dan pembatasan masalah tersebut, maka dalam penelitian ini masalah yang dirumuskan adalah Apakah kualitas pelayanan oriflame dapat mempengaruhi loyalitas pelanggan?

\section{Landasan Teori}

Menurut Kotler (2002:83) menyatakan sebagai berikut :

Pelayanan adalah setiap tindakan atau kegiatan yang dapat ditawarkan oleh suatu pihak kepada pihak lain, yang pada dasarnya tidak berwujud dan tidak mengakibatkan kepemilikan apapun.Produksinya dapat dikaitkan atau tidak dikaitkan pada satu produk fisik. Pelayanan merupakan perilaku produsen dalam rangka memenuhi kebutuhan dan keinginan konsumen demi tercapainya kepuasan pada konsumen itu sendiri. Kotler juga mengatakan bahwa perilaku tersebut dapat terjadi pada saat, sebelum dan sesudah terjadinya transaksi.

Menurut Oliver (2002:84) loyalitas pelanggan adalah sebagai berikut :

Loyalitas pelanggan adalah komitmen yang kuat dari pelanggan untuk berlangganan kembali atau melakukan pembelian ulang produk/jasa yang disukai secara konsisten di masa yang akan datang, meskipun pengaruh situasi dan usaha-usaha pemasaran mempunyai potensi untuk menimbulkan perilaku untuk berpindah.

\section{METODE PENELITIAN}

Penelitian dilaksanakan di lingkungan kampus Politeknik Negeri Jakarta jurusan Administrasi Niaga. Penelitian ini dilaksanakan dengan menyebar kuisioner secara acak.Kuisioner ditujukan kepada pengguna produk Oriflame di lingkungan kampus Politeknik Negeri Jakarta atas dasar kesediaan Mahasiswa untuk dijadikan subjek penelitian.

Menggunakan pendekatan kuantitatif, pemakaian system random sampling dengan teknik Slovin sebesar 5\% dan penelitian ini menggunakan penelitian asosiatif.Teknik pengumpulan data yang digunakan adalah studi lapangan.

Untuk memperoleh data primer digunakan teknik kuesioner yang disebarkan kepada mahasiswa Administrasi Niaga PoliteknikNegeri Jakarta dengan skala penilaian menggunakan skala likert.Teknik pengolahan data menggunakan editing, coding dan tabulating.

Data-data yang diperoleh dari pengisian kuesioner oleh responden, diolah memakai teknik analisis data dan uji korelasi sederhana, uji t, uji regresi sederhana dan uji koefisien determinasi.

\section{HASIL DAN PEMBAHASAN \\ Hasil Uji Validitas}

Tabel 1. Hasil Uji Validitas Pernyataan

Variabel Kualitas Pelayanan (X)

\begin{tabular}{c|c|c|c}
\hline Pernyataan & $\begin{array}{c}\mathrm{r} \\
\text { Hitung }\end{array}$ & $\begin{array}{c}\mathrm{r} \\
\text { Tabel }\end{array}$ & Hasil \\
\hline 1 & 0,873 & 0.707 & Valid \\
\hline 2 & 0,783 & 0.707 & Valid \\
\hline 3 & 0,967 & 0.707 & Valid \\
\hline 4 & 0,804 & 0.707 & Valid \\
\hline 5 & 0,799 & 0.707 & Valid \\
\hline 6 & 0,961 & 0.707 & Valid \\
\hline 7 & 0,865 & 0.707 & Valid \\
\hline 8 & 0,813 & 0.707 & Valid \\
\hline 9 & 0,967 & 0.707 & Valid \\
\hline 10 & 0,873 & 0.707 & Valid \\
\hline 11 & 0,767 & 0.707 & Valid \\
\hline 12 & 0,780 & 0.707 & Valid \\
\hline 13 & 0,955 & 0.707 & Valid \\
\hline 14 & 0,722 & 0.707 & Valid \\
\hline 15 & 0,946 & 0.707 & Valid \\
\hline
\end{tabular}




\begin{tabular}{c|c|c|c}
\hline 16 & 0,767 & 0.707 & Valid \\
\hline 17 & 0,967 & 0.707 & Valid \\
\hline 18 & 0,776 & 0.707 & Valid \\
\hline 19 & 0,722 & 0,707 & Valid \\
\hline 20 & 0,967 & 0,707 & Valid \\
\hline
\end{tabular}

Setelah dilakukan uji coba kuesioner diketahui bahwa 20 butir-butir pernyataan pada variabel kualitas pelayanan dalam kuesioner tersebut merupakan pernyataan yang valid, karena nilai $r$ hitung seluruh pernyataan lebih besar dari nilai $r$ tabel yang di tentukan sebesar (0,707). Seluruh pernyataan yang telah valid tersebut dapat di gunakan sebagai instrumen dalam penelitian selanjutnya.

Tabel 2. Hasil Uji Validitas Pernyataan Variabel Loyalitas Pelanggan(Y)

\begin{tabular}{c|c|c|c}
\hline Pernyataan & r Hitung & $\mathrm{r}$ Tabel & Hasil \\
\hline 1 & 0.718 & 0.707 & Valid \\
\hline 2 & 0,983 & 0.707 & Valid \\
\hline 3 & 0,818 & 0.707 & Valid \\
\hline 4 & 0,944 & 0.707 & Valid \\
\hline 5 & 0,983 & 0.707 & Valid \\
\hline 6 & 0,983 & 0.707 & Valid \\
\hline 7 & 0,825 & 0.707 & Valid \\
\hline 8 & 0,899 & 0.707 & Valid \\
\hline 9 & 0,718 & 0.707 & Valid \\
\hline 10 & 0,983 & 0.707 & Valid \\
\hline 11 & 0,899 & 0.707 & Valid \\
\hline 12 & 0,983 & 0.707 & Valid \\
\hline 13 & 0,983 & 0.707 & Valid \\
\hline 14 & 0,857 & 0.707 & Valid \\
\hline 15 & 0,983 & 0.707 & Valid \\
\hline 16 & 0959 & 0.707 & Valid \\
\hline 17 & 0,983 & 0.707 & Valid \\
\hline 18 & 0,899 & 0.707 & Valid \\
\hline 19 & 0,983 & 0.707 & Valid \\
\hline 20 & 0,713 & 0.707 & Valid \\
\hline Sel
\end{tabular}

Setelah dilakukan uji coba tersebut di ketehaui bahwa 20 pernyataan tersebut telah valid, karena nilai $r$ hitung lebih besar dari nilai $r$ tabel yang telah ditentukan sebesar (0,707).Seluruh pernyataan yang telah valid tersebut dapat di gunakan sebagai instrumen dalam penelitian selanjutnya.

a. Hasil Uji Reliabilitas

Tabel 3. Hasil Uji Reliabilitas Variabel Kualitas Pelayanan (X)

\begin{tabular}{|r|r|}
\hline $\begin{array}{c}\text { Cronbach's } \\
\text { Alpha }\end{array}$ & N of Items \\
\hline, 803 & \\
\hline
\end{tabular}

Dari tabel diatas menjelaskan bahwa hasil uji reliabilitas dan pernyataanpernyataan pada variabel kualitas pelayanan (x) sebesar 0,803. Hal ini menunjukkan bahwa pernyataanpernyataan yang di kaji tersebut memenuhi kriterian reliabilitas dengan nilai Cronbach Alpha lebih besar dari 0,6.

Tabel 4. Hasil Uji Reliabilitas

Variabel Loyalitas Pelanggan (Y)

Reliability Statistics

\begin{tabular}{|r|r|}
\hline $\begin{array}{c}\text { Cronbach's } \\
\text { Alpha }\end{array}$ & N of Items \\
\hline, 790 & \\
\hline
\end{tabular}

Tabel di atas menjelaskan bahwa hasil uji reliabilitas dari pernyataanpernyataan pada variabel loyalitas pelanggan (y) sebesar 0,790. Hal ini menunjukkan bahwa pernyataanpernyataan tersebut telah memenuhi kriterian reliabilitas dengan nilai Cronbach's Alpha lebih besar dari 0,6 .

b. Hasil Uji Korelasi Sederhana

Correlations

\begin{tabular}{|ll|r|r|}
\hline & & TOTALX & TOTALY \\
\hline \multirow{2}{*}{ TOTAL } & Pearson Correlation & 1 & $.660^{* *}$ \\
$\mathrm{X}$ & Sig. (2-tailed) & & \\
& $\mathrm{N}$ & 40 & .000 \\
& & & 40
\end{tabular}




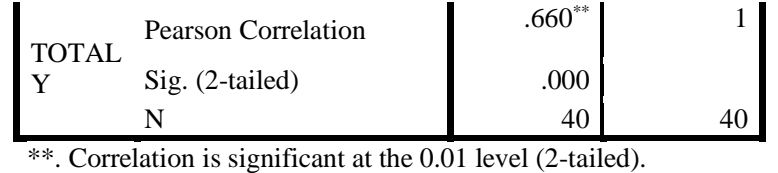

Perhitungan pada analisis korelasi ini menunjukkan hasil dari jawaban responden sebagai sumber penelitian. Perhitungan analisis korelasi ini dilakukan dengan memasukkan total $\mathrm{X}$ dan Y total. Dari hasil analisi korelasi sederhana didapat nilai korelasi antara Kualitas Pelayanan dengan Loyalitas Pelanggan dengan nilai $r$ sebesar 0,660 , Hal ini menunjukkan bahwa pengaruh kualitas pelayanan terhadap loyalitas pelanggan Oriflame di lingkungan mahasiswa Administrasi Niaga Politeknik Negeri Jakarta adalah kuat.

c. Hasil Uji T

\begin{tabular}{l|l}
\hline $\mathrm{t}$ & Sig. \\
\hline 5.263 & .000 \\
\hline 5.418 & .000 \\
\hline
\end{tabular}

Dari data tabel di atas dapat diketahui hasil uji t dengan nilai t hitung sebesar 5,418, dimana nilai tersebut lebih besar dari t tabel yang ditentukan sesuai dengan taraf tingkat kesalahan 5\% sebesar 1,686. Hal ini berarti terdapat pengaruh yang signifikan antara variabel kualitas pelayanan terhadap variabel loyalitas pelanggan.

\section{d. Hasil Uji Regresi}

\begin{tabular}{|rl|r|r|c|}
\hline \multirow{2}{*}{ Model } & \multicolumn{2}{|c|}{$\begin{array}{c}\text { Unstandardized } \\
\text { Coefficients }\end{array}$} & $\begin{array}{c}\text { Standardized } \\
\text { Coefficients }\end{array}$ \\
\cline { 2 - 5 } & \multicolumn{1}{c|}{ B } & Std. Error & \multicolumn{1}{c|}{ Beta } \\
\hline \multirow{2}{*}{1} & (Constant) & 42,509 & 8.077 & \\
& TOTALX & .534 & .099 & .660 \\
\hline
\end{tabular}

Nilai konstanta ini menunjukkan bahwa jika tidak ada kenaikan kualitas pelayanan, maka loyalitas pelanggan akan mencapai $\mathrm{Y}=42,509$, sedangkan nilai
0,534 merupakan koefisien regresi yang menunjukkan bahwa setiap $\mathrm{X}$ ada penambahan 1 nilai atau angka untuk kualitas pelayanan, maka akan ada kenaikan loyalitas pelanggan sebesar 0,534 . Coefficients beta $Y=a+b x$ tersebut bersifat positif yang artinya terdapat pengaruh yang positif antara kualitas pelayanan terhadap loyalitas pelanggan.

e. Koefisien Determinasi

Model Summary

\begin{tabular}{|l|c|r|r|r|}
\hline Model & $\mathrm{R}$ & $\begin{array}{c}\mathrm{R} \\
\text { Square }\end{array}$ & $\begin{array}{c}\text { Adjusted } \\
\text { R Square }\end{array}$ & $\begin{array}{c}\text { Std. Error of } \\
\text { the Estimate }\end{array}$ \\
\hline 1 & $.660^{\mathrm{a}}$ & .436 & .421 & 6.616 \\
\hline
\end{tabular}

a. Predictors: (Constant), TOTALX

Nilai korelasi $\mathrm{R}$ sebesar 0,660 dan nilai $\mathrm{R}$ square sebesar 0,436. Nilai $\mathrm{R}$ square tersebut menunjukkan besarnya pengaruh variabel X (kualitas pelayanan) terhadap variabel Y (loyalitas pelanggan), dimana besarnya pengaruh kualitas pelayanan terhadap loyalitas pelanggan sebesar $43,6 \%$, sedangkan sisanya $56,4 \%$ dipengaruhi oleh variabel lain diluar penelitian ini.

\section{KESIMPULAN DAN SARAN Kesimpulan}

Kualitas Pelayanan memiliki hubungan yang kuat dan memiliki pengaruh yang signifikan dan positif terhadap loyalitas pelanggan di lingkungan mahasiswa Administrasi Niaga Politeknik Negeri Jakarta. Dilihat dari beberapa hasil analisis yaitu analisis koefisien korelasi sebesar 0,660, dilihat dari hasil analisis uji t di peroleh nilai $t$ hitung $(5,418)>t$ tabel $(1,686)$ dengan nilai signifikasi sebesar 0,000 $<0,05$ maka Ha diterima dan Ho ditolak dan hasil uji regresi linear sederhana yang menunjukan nilai koefisien beta positif. 
Saran

Setelah dilakukan penelitian dan sudah diketahui hasilnya maka penulis memberikan saran yaitu perusahaan Oriflame sebaiknya agar dapat terus meningkatkan kualitas pelayanan bagi pelanggan dan dapat meningkatkan keterampilan dalam hal berkomunikasi dengan pelanggan (dealing with customer) yang dapat menunjang pelayanan sehingga kualitas pelayanan Oriflame akan semakin meningkat.

\section{DAFTAR PUSTAKA}

Ali, Hasan. 2008 .Marketing.Yogyakarta : Media Pressindo

Alma, Buchari. 2002 .Manajemen Pemasaran.Bandung : CV Alvabeta

Arikunto, Suharsimi. 2002 .Jakarta : PT.Rineka Cipta

Barata, Atep Adya. 2003 . Dasar-Dasar Pelayanan Prima.Jakarta : PT Gramedia Pustaka

Dharmayanti, Diah. $2006 \quad$.Analisa Sensitivitas Respon Konsumen Terhadap Ekstensi Merek.Surabaya

Griffin, Jill. 2002 . Customer Loyalty: How To Earn It, How To Keep It. Lexington Books, Avenue of Americas, New York.

Juliansyah, Noor. 2012 .Metodologi Penelitian.Jakarta : Prenada Media Group

Kotler, Philip. $2002 \quad$.Manajemen Pemasaran.Jakarta : PT Prenhalindo

Kotler, Philip. 2002 .Manajemen Pemasaran.Jakarta : PT Prenhalindo

Kotler, Philip. Keller, Kevin. 2006 .Manajemen Pemasaran. Jakarta : Ghalia Indonesia

Lupiyoadi, Hamdani. 2006 .Manajemen Pemasaran Jasa.Jakarta: Salemba Empat

Sugiyono. 2003 .Metode Penelitian Bisnis.Bandung : Alfabeta
Sugiyono. $2012 \quad$.Metodologi

Penelitian.Jakarta : Alfabeta

Tjiptono, Fandy. 1996 .Manajemen Jasa.Yogyakarta : Andi Offset

Tjiptono, Fandy. 2001 .Manajemen Jasa.Yogyakarta : Andi Offset

Tjiptono, Fandy. $2007 \quad$ Strategi Pemasaran.Yogyakarta :Andi Offset

Tjiptono, Fandy. 2005 .Pemasaran Jasa.Malang : Bayumedia Publishing

Tjiptono, Fandy. $2007 \quad$ Strategi Pemasaran.Yogyakarta : Andi

Wisnalmawati. 2005 .Pengaruh Persepsi Dimensi Kualitas Layanan terhadap Niat Pembeli Ulang.Jakarta : Salemba Empat 